\title{
OS PROCESSOS DE RECONHECIMENTO, VALIDAÇÃO E CERTIFICAÇÃO DE COMPETÊNCIAS (RVCC) NO ALENTEJO/PORTUGAL: UM DIÁLOGO ENTRE AS DIMENSÕES FORMAIS E NÃO FORMAIS DA EDUCAÇÃO ${ }^{1}$
}

\author{
Lurdes PRATAS NICO² (1) (2) y Fátima FERREIRA (1) \\ (1)Centro de Investigação em Educação e Psicologia da Universidade de Évora \\ (Portugal) \\ (2)Direcção Regional de Educação do Alentejo (Portugal)
}

\section{Introdução}

A presente comunicação destina-se a apresentar, de forma sintética, o Sistema de Reconhecimento, Validação e Certificação de Competências (RVCC), actualmente, existente em Portugal e, em concreto, na região Alentejo.

\section{Método}

A. Fundamentos conceptuais e pedagógicos subjacentes ao paradigma de reconhecimento e validação dos adquiridos experienciais (RVAE)

A sigla RVAE (Reconhecimento e Validação dos Adquiridos Experienciais) remonta ao período do pós-II Guerra Mundial (1945). A partir das décadas de 80 e 90, na Europa, o RVAE afirma-se, cada vez mais, como uma necessidade, por parte dos indivíduos que, ao longo da vida, foram adquirindo experiências e acumulando aprendizagens, a partir das vivências (Santos \& Fidalgo, 2007:82), desenvolvendo-se no contexto de valorização do paradigma de Aprendizagem ao longo da vida. Na V CONFINTEA (Conferência de Hamburgo, 1997) e, em 2000, com a publicação do Memorando sobre a Aprendizagem ao Longo da Vida, valorizou-se cada vez mais a importância aprendizagens adquiridas em contextos não formais e informais.

Apresentam-se, de seguida, alguns dos princípios fundamentais que caracterizam este dispositivo (Nico, 2009:158). a) O primeiro, é aquele que nos remete para o facto de que cada indivíduo aprende com e através da experiência de vida, sendo portadores de competências passíveis de serem reconhecidas e valorizadas através de mecanismos formais, não sendo compreensível que se queira "ensinar" às pessoas aquilo que elas já

\footnotetext{
${ }^{1}$ Comunicação apresentada no âmbito dos projetos de investigação científica "Arqueologia" das Aprendizagens no Alandroal (FCOMP-01-0124-FEDER-007110/ FCT PTDC/CED/81388/2006) e As Novas Núpcias da Qualificação no Alentejo (FCOMP-01-0124-FEDER-009154/FCT PTDC/CPECED/104072/2008), promovidos pelo Centro de Investigação em Educação e Psicologia da Universidade de Évora (CIEP) e financiados pela Fundação para a Ciência e a Tecnologia (FCT).

2 lpnico@@uevora.pt
} 
sabem, mas antes valorizar e reconhecer os saberes experienciais, que se desenvolvem em diversos contextos (Canário, 2006:37; Pires, 2007: 7-8). Há um questionamento do status da Educação Formal e dos diplomas por ela conferidos, deixando a instituição escola formal de ser considerada um local privilegiado de aprendizagem, para passar a ser um dos locais de aprendizagem, numa determinada fase da vida. b) O RVAE pode considerar-se uma prática de inspiração humanista, centrada na valorização do adulto enquanto elemento central de todo o processo. É com base nas suas motivações, disponibilidade, ritmo, experiências e projectos futuros que se desenha todo o percurso com vista ao reconhecimento e validação daquilo que ele próprio foi construindo e aprendendo ao longo da vida (ainda que muitas vezes disso não tenha consciência). c) A experiência e a formação constituem-se como duas formas de aquisição de competências (Spirli, 2006:347). A experiência deve, no entanto, constituir-se como uma experiência significativa, das quais resultem aprendizagens significativas, e nem todas o serão efectivamente, algumas experiências poderão até ser "deformadoras ou reforçar posturas face ao saber que acentuam comportamentos repetitivos." (Couceiro, 2002:31).

\section{B. Dispositivos desenvolvidos em Portugal e noutros contextos internacionais}

Neste segundo ponto, apresentamos a caracterização geral dos dispositivos de Reconhecimento e Validação dos Adquiridos Experienciais (RVAE) em alguns países, com referência a dois países pioneiros nesta matéria (Estados Unidos da América e Canadá).

Nos EUA, a origem do dispositivo de RVAE identifica-se no pós-II Guerra Mundial, associado ao movimento de reinserção dos militares desmobilizados da II Guerra Mundial. A partir de 1945, os militares iniciam reivindicações para regressarem ao mercado de trabalho. O reconhecimento formal poderia permitir-lhes a certificação e, dessa forma, reuniriam melhores condições para integrar esse mercado (Canário, 2006:38). No final dos anos 60 e ao longo da década de 70, o movimento de APL ou APEL (Accreditation of Prior Experiential Learning) teve um forte impulso, destacando-se o CAEL (Council for Adult and Experiential Learning). Desenvolveramse, também, respostas de avaliação das aprendizagens experienciais através de sistemas de créditos e orientações para os intervenientes no processo (Nico, 2009:165-166).

No Québec (numa primeira fase) e depois em Ontário e na British Columbia, verificase a criação do dispositivo, a partir de 1975. Como factores que conduziram à aplicação de um sistema de reconhecimento dos adquiridos, salienta-se a proximidade e a influência dos EUA, as alterações rápidas no mundo do trabalho e a luta das mulheres 
(através dos movimentos feministas nos anos 60, do século passado, no acesso ao ensino superior) que, com o seu contributo, sensibilizaram a sociedade para a consciência da importância das tarefas que exerciam no voluntariado e em casa, no contexto doméstico, valorizando os espaços vitais como espaços de aquisição de saberes e aprendizagens (Pires, 2005). De acordo com a mesma autora, foram implementados diferentes sistemas de reconhecimento: Ensino Secundário, Ensino Colegial, Ensino Universitário. No âmbito do mercado, também se desenvolveram dispositivos de reconhecimento desta natureza, no campo profissional (Reconnaissance des Compétences Professionnelles).

Se noutros países, que não apenas europeus, assistimos, desde cedo, à criação de respostas que permitissem aos cidadãos reconhecer, validar e certificar as suas competências, em Portugal, o dispositivo de Reconhecimento e Validação dos Adquiridos Experienciais (RVAE) viria a ser criado na década de 90, do século XX, e assumiu a designação de Reconhecimento, Validação e Certificação de Competências (RVCC). Em Portugal, a implementação do dispositivo de RVCC desenvolveu-se, em duas fases: a primeira entre 2001-2005, e a segunda entre 2006 e 2010. A génese do dispositivo de RVCC inscreve-se no trabalho desenvolvido pelo Grupo de Trabalho para o Desenvolvimento da Educação de Adultos (Despacho n. ${ }^{\circ}$ 10534/97, de 16 de Outubro) que, em 1997, deu lugar ao Grupo de Missão para o Desenvolvimento da Educação e Formação de Adultos (GMEFA, através da Resolução do Conselho de Ministros n. ${ }^{0} 92 / 98$, de 14 de Julho), o qual foi incumbido de desencadear o processo conducente à constituição da Agência Nacional de Educação e Formação de Adultos, em 1999 (ANEFA, 1999-2002). Face aos baixos níveis de qualificação (sub-certificação formal e informal) era necessário dar uma resposta de qualificação adequada à população adulta ${ }^{3}$. Em 2001 foram, assim, criados, numa iniciativa da ANEFA, os Centros de Reconhecimento, Validação e Certificação de Competências (CRVCC), nos quais se realizaram os primeiros processos de Reconhecimento, Validação e Certificação de Competências.

\section{Caracterização do processo de Reconhecimento, Validação e Certificação de Competências (RVCC)}

Entre 2001 e 2005, existiam em Portugal 98 Centros de RVCC, dos quais 6 na região do Alentejo (Nico, 2011), tutelados pela ANEFA, de acordo com a cronologia que se apresenta de seguida: Esdime (Associação para o Desenvolvimento Local no Alentejo Sudoeste, 2000); Fundação Alentejo (Évora, 2001); Centro de Formação

\footnotetext{
${ }^{3}$ Em 2001, 62\% dos activos tinha uma escolaridade inferior a 9 anos (INE).
} 
Profissional do IEFP, 2001; Associação para o Desenvolvimento do Litoral Alentejano (em Santiago do Cacém, 2003); Rota do Guadiana (Associação de Desenvolvimento Integrado, em Serpa, 2004; Associação Terras Dentro (Alcáçovas Viana do Alentejo, 2005).

O processo de RVCC é concretizado em 3 eixos fundamentais: o eixo do reconhecimento, o eixo da validação e o eixo da certificação.

O eixo de reconhecimento de competências é o "processo de identificação pessoal das competências previamente adquiridas e que se consubstancia no conjunto de actividades, assentes numa lógica de balanço de competências,..."4 $\mathrm{O}$ adulto é acompanhado num processo de reflexão sobre as competências que adquiriu ao longo da vida por via das experiências "quer em contextos formais de aprendizagem e trabalho, quer em contextos informais e não formais", as quais são transferíveis a outras situações (ANEFA, 2002:30, citado por Nico:2009:198). A realização de um processo de RVCC, nomeadamente a partir do processo de Balanço de Competências, implica, por parte do adulto, a construção do Portefólio Reflexivo de Aprendizagens (inicialmente denominado de Dossier Pessoal).

O eixo de validação de competências é o acto através do qual se validam as competências do adulto em função daquilo que está consignado nos Referenciais de Competências-Chave, em sede de reunião que ocorre entre os elementos da equipa pedagógica.

O eixo de certificação de competências "é o processo que confirma as competências adquiridas em contextos formais, não formais e informais e que constitui o acto oficial de registo das competências" " Este registo de competências, actualmente, é efectuado na Caderneta Individual de Competências (Portaria n. ${ }^{\circ}$ 475/2010, de 8 de Julho), onde se registam as competências adquiridas ou desenvolvidas pelo indivíduo ao longo da vida, referidas no Catálogo Nacional de Qualificações.

Os Centros de Reconhecimento, Validação e Certificação de Competências (CRVCC) são, desde o início de 2006, sujeitos a profundas alterações de natureza legal e ao nível organizacional e de gestão, pois os seus objectivos e funções são alterados para que possam estar em conformidade com os princípios preconizados na Iniciativa Novas Oportunidades, no que à população adulta diz respeito, sob a tutela da Agência Nacional para a Qualificação, I.P. (entre 2007 e 2011). Os Centros de RVCC passam a designar-se Centros Novas Oportunidades (Portaria n. 370/2008, de 21 de Maio). O Sistema de RVCC, em 2010, era concretizado numa rede de 453 Centros Novas

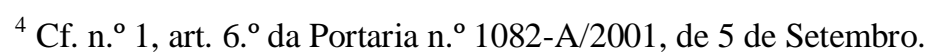

${ }^{5}$ Cf. art. $8 .^{\circ}$ da Portaria n. ${ }^{\circ} 1082-A / 2001$, de 5 de Setembro.
} 
Oportunidades disseminados por todo o país, 40 dos quais na região Alentejo (www.novasoportunidades.gov.pt). Actualmente, o instituto que, a nível central tem a missão de coordenar a rede de Centros Novas Oportunidades e o Sistema de RVCC é a Agência Nacional para a Qualificação e o Ensino Profissional (ANQEP, I.P.). Presentemente, esta rede de $\mathrm{CNO}$, tal como a conhecemos, está numa fase de reorganização, quer ao nível da sua missão, quer na dimensão da rede, numa preocupação de estruturar respostas que promovam a formação profissional e aprendizagem ao longo da vida, de jovens e de adultos.

\section{Referências Bibliográficas}

Anefa (2002). Centros de Reconhecimento, Validação e Certificação de Competências: Roteiro Estruturante. Lisboa: ANEFA.

Canário, R. (2006). "Formação e Adquiridos Experienciais. Entre a pessoa e o indivíduo". In Gérard Figari et al (orgs.). Avaliação de Competências e Aprendizagens Experienciais. Saberes, modelos e métodos. Lisboa: Educa. pp. 35-46.

Couceiro, M. (2002). “O Reconhecimento de Competências”. In Revista Saber Mais, N. ${ }^{\text {1 } 13 . ~ L i s b o a: ~ A N E F A . ~ p p . ~ 30-32 . ~}$

Nico, L. (2009). Avaliação do(s) Impacto(s) do Processo de Reconhecimento, Validação e Certificação de Competências (RVCC), no Alentejo (período 2001-2005) [Tese apresentada à Universidade de Évora tendo em vista a obtenção do Grau de Doutor em Ciências da Educação]. Évora: Universidade de Évora (policopiada).

Nico, L. (2011). A Escola da Vida: Reconhecimento e Validação dos Adquiridos Experienciais em Portugal. Fragmentos de uma Década (2000-2010). Colecção Educação, Território e Desenvolvimento Local. N. ${ }^{\circ}$ 1. Mangualde: Edições Pedago.

Pires, A. (2005). Educação e Formação ao Longo da Vida: análise crítica dos sistemas e dispositivos de reconhecimento e validação de aprendizagens e competências. Lisboa: Fundação Calouste Gulbenkian e Fundação para a Ciência e Tecnologia.

Pires, A. (2007). "Reconhecimento e Validação das Aprendizagens Experienciais. Uma problemática educativa". In Revista de Ciências da Educação Sísifo. N. ${ }^{\circ}$ 2. pp. 5-20. (consultado em http://sisifo.fpce.ul.pt)

Santos, N. \& Fidalgo, F. (2007). “Os (des)caminhos da certificação de competências no Brasil”. In Fernando Fidalgo et al (orgs.). Educação Profissional e a Lógica das Competências. Petrópolis: Editora Vozes. pp.71-110.

Spirli, D. (2006). "La certification: une nouvelle donne pour la qualification des adultes." In Albano Estrela et al (orgs.). Actas do XVII Colóquio ADMEE-Europa. Lisboa: FPCE-UL. pp. 347-354. 